\title{
An outbreak of leptospirosis imported from Germany to Poland
}

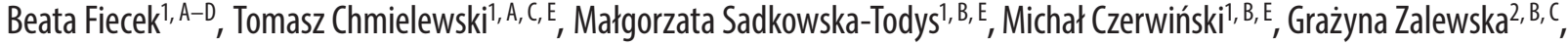 \\ Urszula Roguska ${ }^{1, B}$, Stanisława Tylewska-Wierzbanowska, ${ }^{1, C, C, E, F}$ \\ ${ }^{1}$ National Institute of Public Health - National Institute of Hygiene, Warszawa, Poland \\ ${ }_{2}^{2}$ Provincial Sanitary-Epidemiological Station, Wrocław, Poland \\ A - research concept and design; $\mathrm{B}$ - collection and/or assembly of data; $\mathrm{C}$ - data analysis and interpretation; \\ $D$ - writing the article; $E$ - critical revision of the article; $F$ - final approval of article
}

\section{Address for correspondence}

Tomasz Chmielewski

E-mail: tchmielewski@pzh.gov.pl

Funding sources

Financial suport: NIPH-NIH funds (18/EM/2015).

Conflict of interest

None declared

Received on July 06, 2015

Revised on January 03, 2016

Accepted on March 02, 2016

DOI

10.17219/acem/62022

\section{Copyright}

Copyright by Author(s)

This is an article distributed under the terms of the

Creative Commons Attribution Non-Commercial License

(http://creativecommons.org/licenses/by-nc-nd/4.0/)

\section{Abstract}

Background. Leptospirosis is a zoonotic disease caused by spirochetes of the Leptospiraceae family. In both humans and animals the main route of infection is indirect contact - through water or other products contaminated with urine containing spirochetes. Infection most commonly occurs through ingestion of water or food contaminated with Leptospira spp.

Objectives. The aim of the study was to characterize cases of leptospirosis imported to Poland from Germany in 2014 and to analyze methods that are helpful for making a diagnosis.

Material and methods. The 10 patients examined were reported as suspected leptospirosis cases on the basis of clinical symptoms and epidemiological investigations. They originated from different regions of Poland and had been working together at a strawberry plantation in the Cloppenburg district of Lower Saxony in Germany. Blood and urine samples were tested by PCR and serum samples by serology. All ELISA positive and negative cases were examined using a reference microscopic agglutination test (MAT).

Results. In the tested group, 6 individuals (60\%) were seropositive according to the ELISA, and 2 of them were confirmed by the MAT. The PCR results for the blood and urine samples were negative.

Conclusions. Using the ELISA in the diagnosis of leptospirosis allowed the disease to be identified much faster, differentiating classes of antibodies and recognizing levels of them that are too low to be detectable by the MAT.

Key words: ELISA, outbreak, leptospirosis, diagnosis 
In August 2014, a leptospirosis outbreak was recognized in Poland. All the infected people originated from different regions of Poland, and all had worked during the summer on a strawberry plantation in Germany.

Leptospirosis is a zoonotic disease caused by spirochetes of the Leptospiraceae family. In animals, the course of the disease is asymptomatic. Spirochetes colonize the renal tubules of the hosts and a large number of them are excreted into the environment with the urine. ${ }^{6,10}$ In both humans and animals the main route of infection is indirect contact -through water or other products contaminated with urine containing spirochetes. Infection most commonly occurs through ingestion of water or food contaminated with Leptospira spp.

In humans the disease is usually biphasic. The first stage - bacteremia (leptospiremia) - persists for one week, followed by the second stage, with immune response and leptospiruria. The second stage can lead to tissue damage directly by leptospira or by inflammatory processes developed as a result of the infection. In humans, leptospirosis has various clinical pictures, from fever of unknown origin or flu-like illness to the classic form of Weil's disease or meningitis. Many patients show spontaneous recovery within 10-14 days..$^{9-11}$ Leptospira spp. can survive several months in the intraocular fluid, occasionally causing chronic, recurrent uveitis. ${ }^{11}$ These bacteria may be also excreted with the urine for several months after infection. ${ }^{6}$

Certain professions are associated with increased risk of infection, including farmers, miners, veterinarians, sewage systems workers and garbage collectors. Leptospirosis outbreaks have been observed in Poland in various regions, mainly in Southern Poland. ${ }^{3,8,15}$ Most cases were identified by the clinical symptoms and physical examination. In the period from 2009 to 2012 sporadic cases requiring hospitalization were reported. According to national epidemiological data, from 2011 to 2013, only 6 cases were reported. However, the number of recognized cases probably underestimated the actual number, due to limited laboratory capacity. In Poland, only 3 medical laboratories are equipped to diagnose leptospirosis and this is probably the reason for such a low number of recognized cases.

The host's humoral response plays a major role in Leptospira spp. infection, so serological tests are useful in identifying the infection. IgM antibodies specific for Leptospira spp. are detectable as early as 5-7 days after the onset of the first symptoms of the disease, and they persist for at least 5 months. Detecting these antibodies is evidence of acute and/or active infection. IgG antibodies are detected 7 days after the onset of symptoms and persist for years. ${ }^{1,7}$

Laboratory methods for identifying leptospirosis include urine culture, a reference microscopic agglutination test (MAT), an enzyme-linked immunosorbent assay (ELISA), and an immunofluorescence assay (IFA). Bacteria are isolated from human blood, urine and cere- brospinal fluid, depending on the stage of the disease., ${ }^{9,12}$ Molecular diagnostic methods are also used, mainly the polymerase chain reaction (PCR). DNA gene fragments of Leptospira spp. have been detected in various clinical specimens including serum, urine, aqueous humor of the eye and tissue sections. ${ }^{13}$

Based on the results of amplification reactions and gene fragment sequencing it is possible to determine pathogenic and non-pathogenic human and animal leptospira strains. ${ }^{4,13}$ It is especially useful to apply molecular methods in the incubation stage of the disease, when the specific antibodies are produced. DNA is detected in the blood during the first 5-15 after the onset of symptoms. The number of bacteria in the serum at that time ranges from $10^{5}$ to $10^{9}$ leptospira/L. The results of an ELISA (class of IgM antibodies) and PCR in clinical materials taken at the same time are positive in about $60 \%$ of infected individuals. ${ }^{13}$

The aim of the present study was to characterize all the cases of leptospirosis imported to Poland from Germany in 2014, and to analyze laboratory methods helpful for identifying the infection.

\section{Material and methods}

Material was collected from 10 individuals returning from Germany (4 women and 6 men) with suspected leptospirosis. Two of the women were 45 years old, and the others 22 and 23 years old; the men were 18, 20, 21, 23, 26 and 56 years old. They presented with high fever $\left(39-40^{\circ} \mathrm{C}\right)$, chills, myalgia, and flu-like symptoms. All but patient 5 were hospitalized 1 to 7 days after the onset of symptoms, and they were treated with antibiotics immediately. Patient 5 was treated at a community health center. Detailed characteristics of the patients are presented in Table 1. In differential diagnosis, sciatica was initially diagnosed in patient 5. Patient 9 was tested for HAV, HBV, HCV, Mycobacterium tuberculosis, Chlamydophila pneumoniae and Bordetella pertusis infections. Urine and blood cultures were performed in all the patients; in patients 6 and 9 the cerebro-spinal fluid was cultured as well.

The blood and urine samples for leptospirosis tests were obtained from the patients between August 18 and September 3 of 2014.

\section{Serological tests}

\section{ELISA}

IgM and IgG antibodies to Leptospira spp. spirochetes were tested in sera with the ELISA method (Serion Classic, Institut Virion-Serion GmbH, Wurzburg, Germany). Seropositive sera were examined using a reference MAT. 


\section{MAT (microscopic agglutination test)}

The 16 serovars used were Leptospira interrogans species: Icterohaemorrhagiae, Canicola, Zanoni, Autumnalis, Bataviae, Hebdomadis, Australis and Pomona; Leptospira borgpeterseni species: Poi, Ballum, Tarassovi, Sejroe and Mini; Leptospira weilii species: Celledoni; and Leptospira kirschneri species: Cynopteri and Grippotyphosa.

Titers of $1: 400$ and higher were considered a confirmation of leptospirosis.

\section{DNA preparation}

Bacterial DNA was extracted from serum and urine samples with the QIAamp Tissue kit (QIAGEN GmbH, Hilden, Germany) according to the manufacturer's instructions. Concentrations of the extracted DNA, expressed as optical density, were measured with a BioPhotometer (Eppendorf, Hamburg, Germany) at $260 \mathrm{~nm}$. The DNA samples were stored at $-20^{\circ} \mathrm{C}$ until tests were performed.

\section{PCR}

The extracted DNA samples were amplified to detect fragments of Leptospira spp. gene using primer pairs:

a) Amul (5'-CGC GCT GCA GTT ACT TAG TCG CGT CAG AAG-3') and Amu 2 (5'-CGC GGT CGA CGC TTT CGG TGG TCT GCC AAGC-3'), which are complementary to the LipL32 gene fragment (occurring only in pathogenic species of spirochetes). These primers amplify a $756 \mathrm{bp}$ fragment of the LipL32 gene.

b) G1(5'-CTG AAT CGC TGT ATA AAA GT-3') and G2 (5'-GGA AAA CAA ATG GTC GGA AG-3'), which amplify a 285 bp fragment (plasmid DNA).

The $50 \mu \mathrm{L}$ reaction mixtures contained PCR buffer with $200 \mu \mathrm{M}$ dNTPs, 50 pmol of each primer and $2.5 \mathrm{U}$ HotStar Taq Plus DNA polymerase (QIAGEN GmbH, Hilden, Germany). An aliquot of $5 \mu \mathrm{L}$ of DNA template was added to each reaction mixture. The cycling conditions were as follows: $3 \mathrm{~min}$ at $95^{\circ} \mathrm{C}$, followed by 40 cycles of $30 \mathrm{~s}$ of denaturation at $95^{\circ} \mathrm{C}, 30 \mathrm{~s}$ of annealing at $60^{\circ} \mathrm{C}$ and $61^{\circ} \mathrm{C}$, 1 min of elongation at $72^{\circ} \mathrm{C}$ and finally 7 min of elongation at $72^{\circ} \mathrm{C}$. PCRs were performed in a Mastercycler gradient apparatus (Eppendorf, Hamburg, Germany). Each run of PCR testing included positive and negative controls (DNA from the strains collection and water, respectively). All the amplicons were analyzed in electrophoresis with $1.5 \%$ agarose gel stained with Midori Green Advance DNA Stain (Nippon Genetics Europe GmbH, Dueren, Germany).

\section{Results}

The patients examined had been reported as suspected leptospirosis cases on the basis of clinical symptoms and epidemiological findings. Epidemiological investigations showed that the examined individuals originated from different regions of Poland and that they had been working together at a strawberry plantation in the Cloppenburg district of Lower Saxony in Germany. All 10 of the examined individuals worked on the strawberry plantation along with 4 other Polish individuals hospitalized in Germany due to leptospirosis presenting as Weil's disease. The precise dates when they worked in this region during the summer were not available.

All but 1 of the 10 patients were hospitalized in Poland; the exception (Patient 5) was treated at a community health center. IgM specific Leptospira spp. antibodies were detected in 6 of the patients and IgG in 2 of them. The main symptoms of the infected individuals were fever (approx. $40^{\circ} \mathrm{C}$ ), chills, muscle and joint pain and headaches. Two patients presented meningitis, and 1 patient developed renal impairment (Table 1).

Four seronegative individuals had similar symptoms to those presented by seropositive ones. The diagnosis of leptospirosis in those patients was based on epidemiological data from anamnesis, negative blood and urine cultures and other negative test results. Those 4 patients did not agree to, or did not report for, the control tests.

All ELISA positive and negative cases were examined using a MAT. Positive results were confirmed by MAT for 2 individuals. Based on the results of the MAT, Leptospira kirschneri (Grippotyphosa titer 1:800 and Cynopteri titer $1: 400$ ) was the species that caused the infection.

All of the PCR results for the blood and urine samples were negative: Bacterial DNA was undetectable in the blood and urine.

Ceftriaxone was the medication most frequently used to treat the patients examined; other antibiotics used were ampicillin, amoxicillin and ciprofloxacin. Because of the serious condition of patients 8, 9 and 10, empirical treatment with ciprofloxacin and amoxicillin or ciprofloxacin and tarcefoksym was recommended. All the seropositive patients were cured and discharged in good general condition.

\section{Discussion}

In August 2014, a leptospirosis outbreak was recognized in Poland. The patients had been infected outside Poland, on a strawberry plantation in Germany, and the disease spread across the border. International travel as well as regional environmental and occupational exposure now constitute a major independent risk factor for disease acquisition. ${ }^{3}$

Saito et al. reported that in 2014 soil and environmental water were collected and cultured using "a novel combination of five antimicrobial agents for selective isolation of Leptospira from contaminated samples". ${ }^{16}$ They found that both saprophytic Leptospira spp. and pathogenic 


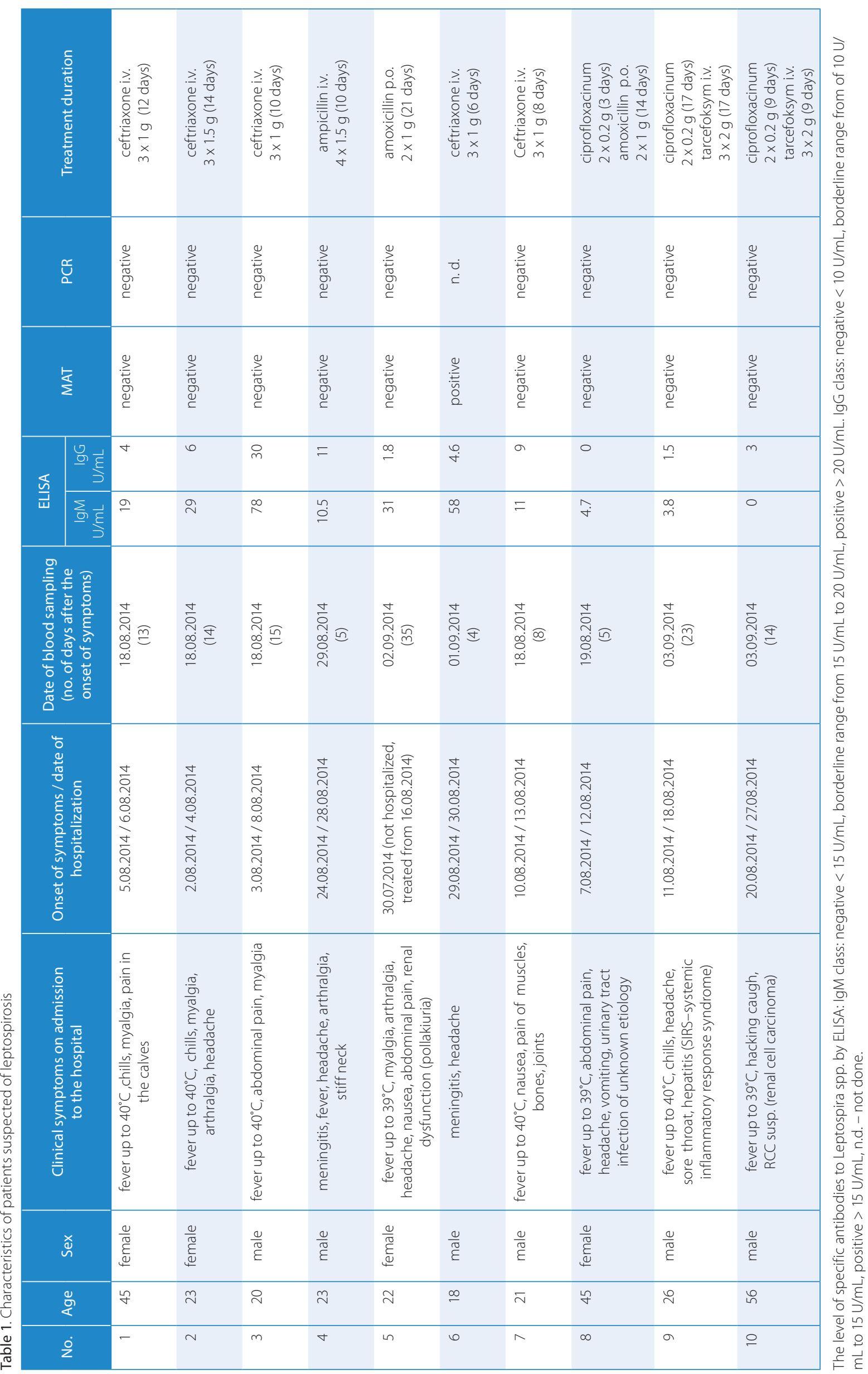


Leptospira spp. are widely distributed in the environment, and "hypothesized that soil serves as a reservoir for Leptospira spp. and infectious source for leptospirosis". ${ }^{16}$

Similar outbreaks of leptospirosis among seasonal strawberry harvesters that have been reported recently pointed out the difficulties with early recognition of the disease. ${ }^{5}$ Leptospirosis has frequently been overlooked or misdiagnosed due to its varied clinical presentations, which range from relatively mild symptoms, such as headache or nausea, to more severe forms, associated with meningitis or renal impairment.

This highlights the need for rapid diagnostic tests for early screening of leptosirosis to replace the less sensitive MAT in outbreak investigations. In the group examined in the present study only 2 patients with seropositive ELISAs were confirmed by MAT (Table 1 ).

Cultures and the serological MAT method are both laborious and time-consuming. At the same time the results obtained are not clear-cut. Identification of Leptospira species using MAT requires constant maintenance of live cultures of multiple strains representing different serotypes of each spirochete species (recognized species of these bacteria have been classified into 25 serogroups and 300 serotypes, therefore it is very difficult to collect and maintain cultures of all of them). Interpretation of the MAT result of a single serum sample is also difficult. Therefore, examinations of paired sera or several repetitions for every patient are needed to monitor dynamic of antibody levels. ${ }^{14}$ ELISA kits, on the other hand, detect antibodies specific to all Leptospira serogroups. Moreover, these tests allow the class of antibodies to be determined.

For the purposes of the current study, ELISA IgM class antibodies were the best parameter, regardless of the stage of disease, because not all patients produce IgG antibodies. A diagnostic ELISA test was used to detect the presence of specific antibodies in both IgM and IgG classes to obtain information about the complete immune condition of the patient. In 1995 Silva et al. studied 2 groups of leptospirosis patients, 57 of them in the acute phase and 10 during convalescence. IgM class antibodies were detected on the $2^{\text {nd }}$ day of symptomatic disease and were observed in $100 \%$ of patients up to the $5^{\text {th }}$ month. Further, $66.7 \%$ of the patients had IgM class antibodies after 7 months, and $50 \%$ had them after the $12^{\text {th }}$ month of the onset of symptoms. IgG class antibodies were detected on the $7^{\text {th }}$ day of symptomatic disease in $9.1 \%$ of the patients, with maximum reactivity $(87.5 \%)$ between the and $3^{\text {rd }}$ months; they were not detected at all in 1 patient. ${ }^{17}$ Early detection of specific IgG antibodies and IgM antibodies may indicate reinfection. ${ }^{16}$

Moderately increased IgM titers accompanied by low IgG titers have also been found. As early as 1985, Terpstra et al. observed that the combination of moderately increased IgM titers and low IgG titers was most often observed in the first 10 day of the disease. This characteristic pattern was found in approximately $2 / 3$ of the sera obtained from leptospirosis patients during the acute phase of the disease. Terpstra et al. also confirmed observations by Adler et al. that it was not always possible to demonstrate specific IgG in the first few weeks after the onset of disease. ${ }^{2,18}$

\section{Conclusions}

Using the ELISA in diagnosing leptospirosis allowed the disease to be identified much faster, differentiating the class of antibodies and recognizing them at levels too low to be detectable by the MAT. In the near future, however, it is necessary to develop an appropriate, sensitive PCR method and to establish appropriate materials and testing times using the ELISA and MAT, to complete the determination and recognition Leptospira species.

\section{References:}

1. Abdulkader RC, Daher EF, Camargo ED, Spinosa C, da Silva MV. Leptospirosis severity may be associated with the intensity of humoral immune response. Rev Inst Med Trop Sao Paulo. 2002;44:79-83.

2. Adler B, Murphy AM, Locarnini SA, Faine S. Detection of specific anti-leptospiral immunoglobulins $M$ and $G$ in human serum by solid-phase enzyme-linked immunosorbent assay. J Clin Microbiol. 1980;11:452-457.

3. Bandara M, Ananda M, Wickramage K, Berger E, Agampodi S. Globalization of leptospirosis through travel and migration. Global Health. 2014;12:10-61.

4. Bluszcz G, Ciszek Z. Leptospirosis according to the data of the infectious disease department of the municipal hospital in Raciborz in the years 1966-1977. Przegl Epidemiol. 1979;33:515-518.

5. Brenner DJ, Kaufmann AF, Sulzer KR, Steigerwalt AG, Rogers FC, Weyant RS. Further determination of DNA relatedness between serogroups and serovars in the family Leptospiraceae with a proposal for Leptospira alexanderi sp. nov. and four new Leptospira genomospecies. Int J Syst Bacteriol. 1999;2:839-858.

6. Emond R, Rowland HAK, Welsby P. Atlas of infectious diseases. Springer PWN, Warszawa; 1996.

7. Evangelista KV, Coburn J. Leptospira as an emerging pathogen: A review of its biology, pathogenesis and host immune responses. Future Microbiol. 2010;5:1413-1425.

8. Hałat Z, Korczyńska A, Kasiński J. The epidemic of leptospirosis in the Wroclaw province in the 1974 year. Przegl Epidemiol. 1976;30:491-495.

9. Levett PN. Leptospirosis. Clin Microbiol Rev. 2001;14:296-326.

10. Magdzik W, Naruszewicz-Lesiuk D, Zieliński A. Infections and infestations. Epidemiology and prevention. Alfa-medica press, BielskoBiała; 2007.

11. Mandell GL, Douglas JE, Bennett JE. Principles and practice of infectious diseases. Churchill Livingstone, New York; 1996.

12. Murray PR, Baron EJ, Pfaller MA, Tenover FC, Yolken RH. Manual of Clinical Microbiology. ASM Press, Washington DC; 1995.

13. Musso D, La Scola B. Laboratory diagnosis of leptospirosis: A challenge. J Microbiol Immunol Infect. 2013;46:245-252.

14. Ooteman MC, Vago AR, Koury MC. Evaluation of MAT, IgM ELISA and PCR methods for the diagnosis of human leptospirosis. J Microbiol Methods. 2006;65:247-257.

15. Pawlicka-Kurek H. Leptospirosis in the Katowice province in the years 1968-1976. Przegl Epidemiol. 1978;32:189-193.

16. Saito M, Yam VS, Masuzawa T, Yanagihara Y, Yoshida S. Leptospirosis now-the centennial of the discovery of Weil's disease pathogen. Nihon Saikingaku Zasshi. 2014;69:589-600.

17. Silva MV, Camargo ED, Batista $L$, et al. Behaviour of specific lgM, lgG and IgA class antibodies in human leptospirosis during the acute phase of the disease and during convalescence. J Trop Med Hyg. 1995;98:268-272.

18. Terpstra WJ, Ligthart GS, Schoone GJ. ELISA for the detection of specific IgM and lgG in human leptospirosis. J Gen Microbiol. 1985;131:377-385. 